\title{
Spontaneous bilateral rod fracture of malleable penile prosthesis
}

\author{
Ibrahim Halil Bozkurt, MD; Tarik Yonguc, MD; Burak Arslan, MD; Zafer Kozacioglu, MD; \\ Tansu Degirmenci, MD; Salih Polat, MD; Suleyman Minareci, MD
}

Izmir Bozkyaka Training and Research Hospital, Izmir, Turkey

Cite as: Can Urol Assoc J 2014;8(9-10):e739-40. http://dx.doi.org/10.5489/cuaj.2005 Published online October 22, 2014.

\section{Abstract}

Mechanical failure with a malleable penile prosthesis is very rare. To the best of our knowledge, this is the first case reporting on a bilateral AMS 650 rod mechanical failure. We present a 50 -yearold man with organic erectile dysfunction who experienced bilateral AMS 650 rod fracture after 14 years. The rod fracture of the left side was confirmed via X-ray preoperatively. The surgical exploration revealed a fracture of both rods. After the removal of both rods, we implanted a new malleable device during the same session. At the 6-month follow-up, the patient was satisfied with his prosthesis.

\section{Introduction}

Penile prosthesis implantation is the gold standard to treat patients with erectile dysfunction who have failed first- and second-line treatments or who have found the implants unacceptable. Penile prosthetic devices can be broadly divided into 2 groups: inflatable devices and malleable ones. The malleable penile prostheses have the advantages of easy implantation, low cost, less mechanical failure and ease of use. Mechanical failure of a malleable penile prosthesis is very rare. ${ }^{1}$ To the best of our knowledge, this is the first reported breakage of both rods of the AMS 650 malleable penile prosthesis (American Medical Systems, Minnetonka, $\mathrm{MN})$.

\section{Case report}

A 36-year-old man with organic erectile dysfunction due to corporeal veno-occlusive dysfunction came to our clinic for treatment with an AMS 650 malleable penile prosthesis in 1999. His postoperative follow-up was uneventful and he had been satisfied with the device for 14 years. In 2014, he complained of a decrease in penile rigidity, bending of the penis to the left side and a crackling sound during sexual intercourse lasting for the preceding 6 weeks. On physical examination, the left and right rods were instable at $1 / 3$ proximal and $1 / 3$ distal parts, respectively. There was no edema, local tenderness or erythema on the sites of instability. The broken part of the left rod was confirmed by plain X-ray film (Fig. 1).

On further questioning, the patient stated that he did not have any vigorous intercourse or any trauma that may have caused the breakage. Surgical exploration was performed through a midline penoscrotal incision. The corporal bodies were intact. After the removal of both rods, we implanted a new malleable device during the same session (Fig. 2, Fig. 3).

\section{Discussion}

Mechanical malfunction is very rare in malleable penile prosthesis. Minervini and colleagues reported 2 cases of mechanical failure (1 with AMS 600 and 1 with Mentor malleable (Mentor, Goleta, CA) in their series of 393 malleable penile prostheses implants. ${ }^{1}$ In these cases, the fractures also occurred late (after 79 months with Mentor malleable, after 112 months with AMS 600) as is seen in our case. Lee and colleagues $^{2}$ reported on the first 2 cases of bilateral malleable penile prosthesis breakage with AMS 600 malleable penile prosthesis (62 and 78 months after implantation).

The AMS 650 malleable penile prosthesis has a fabricwrapped stainless steel core covered with a synthetic braid. The outer layer consists of a silicone elastomer body that provides considerable girth. The first case of mechanical failure with AMS 650 malleable penile prosthesis was reported in $2007 . .^{3}$ In this case, the fracture was unilateral and determined after 6 years. Interestingly, this prosthesis and the prosthesis in our report were implanted in the same year in the same country, but at different institutions. 


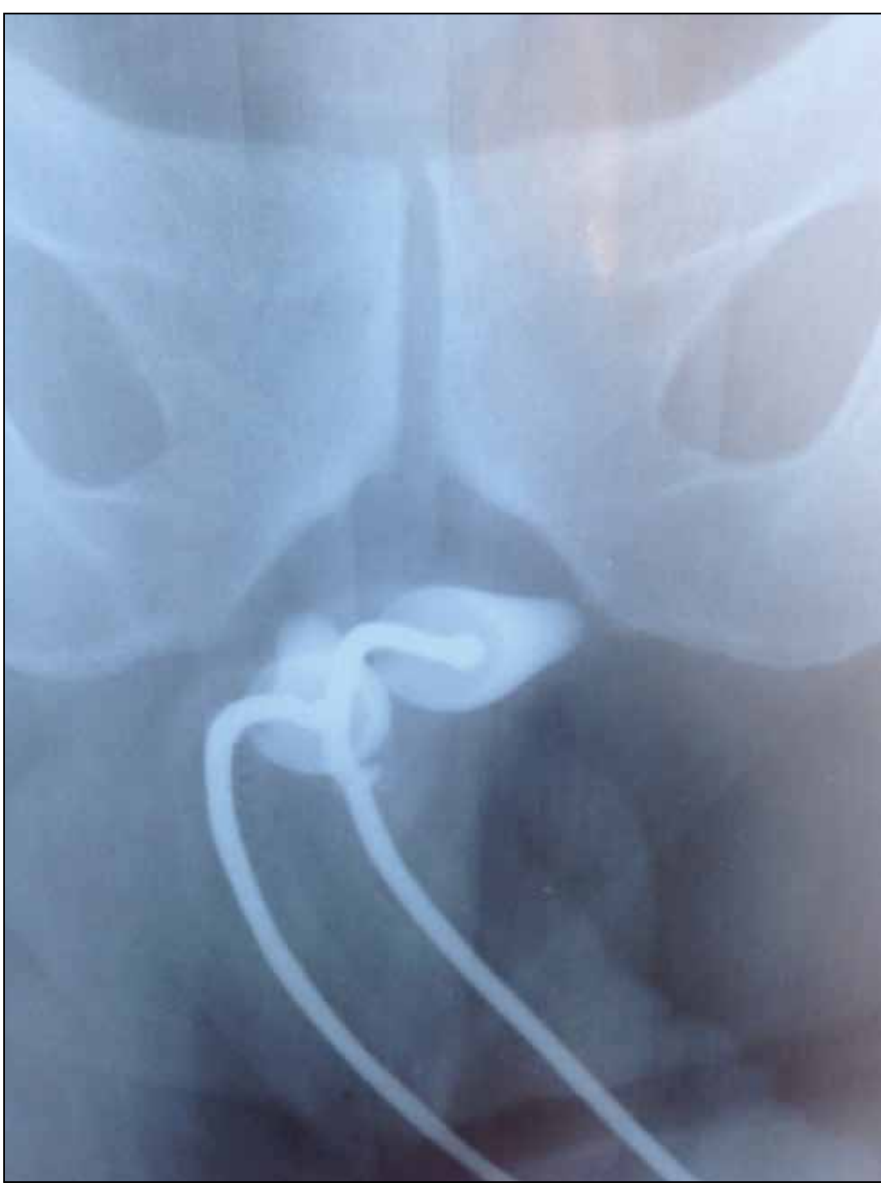

Fig. 1. X-ray film showing the left rod fracture.

\section{Conclusion}

To the best of our knowledge, our case is the first published report about bilateral rod fracture of AMS 650 malleable penile prosthesis. The mechanical failure of malleable penile prosthesis can be seen as a late complication in clinics that perform large numbers of penile prosthesis surgery.

Competing interests: Dr. Bozkurt, Dr. Yonguc, Dr. Arslan, Dr. Kozacioglu, Dr. Degirmenci, Dr. Polat and Dr. Minareci all declare no competing financial or personal interests.

This paper has been peer-reviewed.

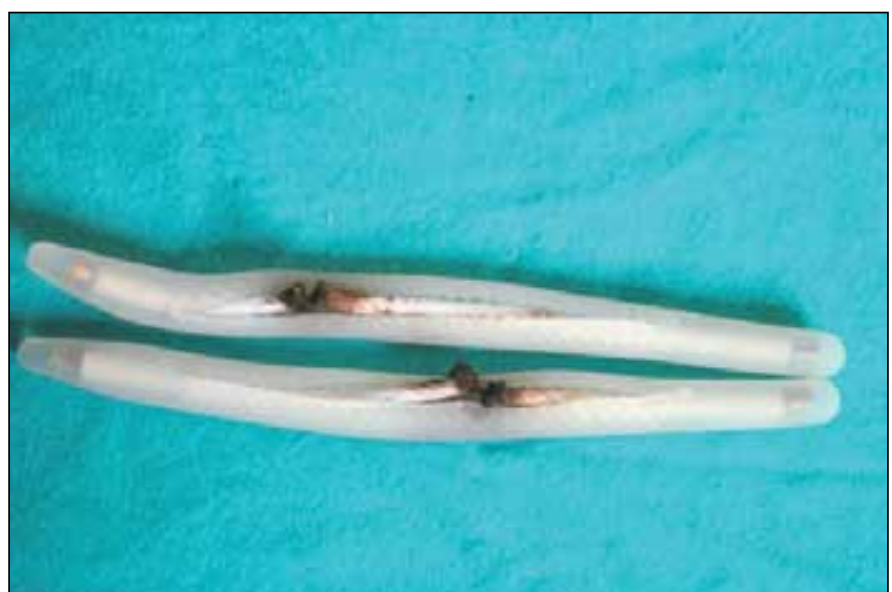

Fig. 2. Bilateral AMS 650 rod fracture.

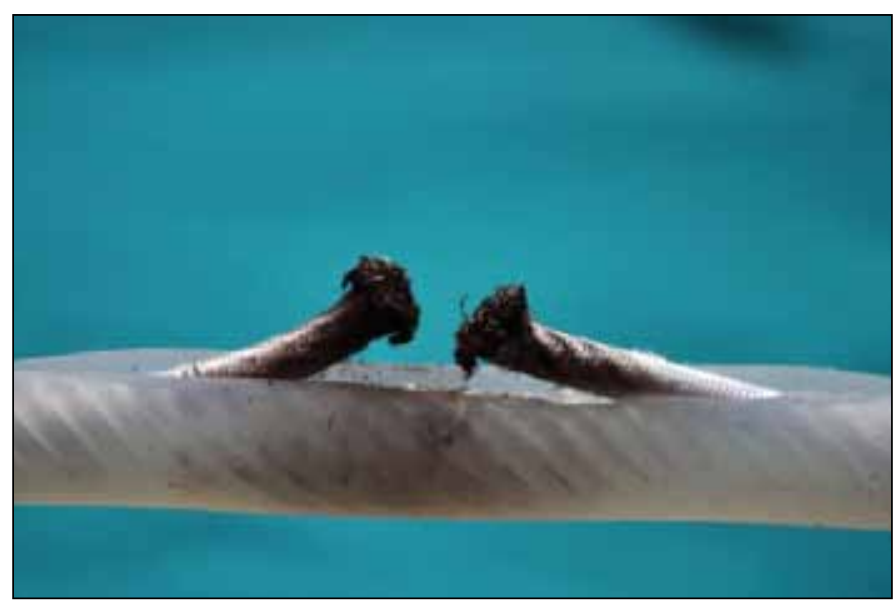

Fig. 3. Broken rod, closer view.

\section{References}

1. Minervini A, Ralph DJ, Pryor JP. Outcome of penile prosthesis implantation for treating erectile dysfunction: Experience with 504 procedures. BJU Int 2006;97:129-33. http://dx.doi.org/10.1111/i.1464410X.2005.05907.x

2. Lee WH, Xin ZC, Choi YD, et al. Spontaneous breakage of malleable penile prosthesis. Int I Impot Res 1998;10:255-6. http://dx.doi.org/10.1038/si.iji.3900349

3. Akand M, Ozayar A, Yaman 0, et al. Mechanical failure with malleable penile prosthesis. Urology 2007;70:1007. htrp://dx.doi.org/10.1016/j.urology.2007.08.005

Correspondence: Dr. Ibrahim Halil Bozkurt, Izmir Bozkyaka Training and Research Hospital, Izmir, Turkey; ihalilbozkur@yahoo.com 